\title{
Early and late hydration of supersulphated cements of blast furnace slag with fluorgypsum
}

\author{
M.E. Bazaldúa-Medellín ${ }^{\mathrm{a}}$, A.F. Fuentes ${ }^{\mathrm{a}}$, A. Gorokhovsky ${ }^{\mathrm{b}}$, J.I. Escalante-García $\bowtie$ \\ a. Cinvestav Unidad Saltillo, (Saltillo, Coahuila, México) \\ b. Saratov State Technical University Russia, (Russia) \\ \ivan.escalante@cinvestav.edu.mx
}

\author{
Received 16 July 2013 \\ Accepted 03 March 2014 \\ Available on line 09 February 2015
}

\begin{abstract}
The hydration, strength development and composition of hydration products of supersulphated cements were characterized from the first 48 hours up to 360 days. Two compositions of $80 \%$ Blast furnace slag, $10-15 \%$ Fluorgypsum and 10-5\% Portland cement were cured in dry and wet conditions. The main hydration products were ettringite and C-S-H since the first hours and up to 360 days as evidenced by X-ray diffraction, thermal analysis and electron microscopy. The strength was favored by higher fluorgypsum contents and lower Portland cement contents. These cements generated heats of hydration of $40-57 \mathrm{KJ} / \mathrm{Kg}$ after 28 hours, which are lower than portland cement.
\end{abstract}

KEYWORDS: Supersulphated; C-S-H; Ettringite; hydration; microstructures

Citation/Citar como: Bazaldúa-Medellín, M.E.; Fuentes, A.F.; Gorokhovsky, A.; Escalante-García, J.I. (2015) Early and late hydration of supersulphated cements of blast furnace slag with fluorgypsum. Mater. Construcc. 65 [317], e043 http://dx.doi.org/10.3989/mc.2015.06013.

RESUMEN: Hidratación temprana y tardía de cementos supersulfatados de escoria de alto horno con fluoryeso. Se realizó la caracterización de la hidratación, desarrollo de resistencia y la composición de los productos de hidratación de los cementos supersulfatados durante las primeras 48 horas y hasta 360 días. Se estudiaron dos composiciones de $80 \%$ de Escoria de alto horno, 10-15\% de Fluoryeso y 10-5\% de Cemento portland, se curaron en condiciones secas y húmedas. Los principales productos de hidratación fueron etringita y C-S-H desde las primeras horas y hasta 360 días, como se evidenció por difracción de rayos X, análisis térmico y microscopía electrónica de barrido. La resistencia se favoreció con mayor contenido de fluoryeso y bajos contenidos de cemento portland. Estos cementos generaron calores de hidratación de $40-57 \mathrm{KJ} / \mathrm{Kg}$ después de 28 horas, los cuales resultan más bajos que los generados por el cemento portland.

PALABRAS CLAVE: Supersulfatado; C-S-H; Etringita; hidratación; microestructuras

Copyright: (C) 2015 CSIC. This is an open-access article distributed under the terms of the Creative Commons Attribution-Non Commercial (by-nc) Spain 3.0 License.

\section{INTRODUCTION}

Although concrete as a construction material is environmentally more convenient than other construction materials like plastics, glass, steel and aluminum, the industry is interested in causing the least possible environment impact throughout the reuse of wastes as aggregates or in binders.
The study and development of cementitious materials alternative to portland cement $(\mathrm{PC})$ has been of interest to reduce the environmental impact caused by the production of the latter; one route is the use of inorganic industrial wastes as partial or full replacement of PC. Blast furnace slag (BFS) is one of such resources, and it is a byproduct of pig iron production, which when rapidly cooled forms 
a highly reactive glassy material that has latent cementitious characteristics; its worldwide yearly production is of about 150 million ton (1).

The potential of the BFS as a cementitious material depends on its reactivity, which is greatly influenced by factor such as the surface area, vitreous fraction and chemical composition. In order to exploit the cementitious nature of the BFS, an activation process is necessary. Mechanical activation is attained by increasing its surface area; on the other hand, chemical activation is possible by means of several reagents, mainly alkalis, sulfates, PC, etc., resulting in cements of strength and durability sometimes higher than those of PC. This makes the BFS an excellent alternative cementitious material for mortar and concrete applications.

Among the chemical activation routes for the BFS, that with sulfates has been successfully used for years in what is known as supersulphated cements (SC). These green cements are regaining attention and are thought to have promising potential for different applications (2). The SC have hydraulic character and consist of $80-85 \%$ BFS, $10-15 \%$ of a source of calcium sulphate and an alkaline media that can be PC (3), hydrated lime (4) or other compounds. The main hydration products are reported as ettringite and calcium silicate hydrates (C-S-H) (5-7). Among the advantages of SC over PC are their resistance to the aggressive attack of sulphates and the low heat of hydration (8).

There are not many reports in the literature on the mechanical properties and microstructural studies of supersulphated cements using various compositions. An early report by Midgley and Pettifer (9) on pastes with $88 \%$ BFS, $10 \%$ gypsum and $2 \%$ PC, described microstructures formed by the formation of long laths of abundant ettringite with plate like C-S-H in the interstices; on the other hand, the pastes developed strength very rapidly, with 30 and $94 \%$ of the 1 year strength (undisclosed) after 1 and 28 days, respectively.

Bijen and Niël (10) reported on mortars and concretes cured for up to 56 days, using a commercial SC and laboratory formulations made with several slags at $79-83 \%, 2-7 \%$ clinker and $14-15 \%$ of calcium sulphates (phosphogypsum or fluorgypsum). The chemical composition of the slags showed a strong influence on the strength development. A mortar with a SC with $83 \%$ BFS, $15 \%$ fluorgypsum and $2 \%$ clinker showed the highest strengths of 9,45 and $58 \mathrm{MPa}$ after 1, 7 and 56 days, respectively; while the commercial SC showed 1, 42 and $75 \mathrm{MPa}$ for the same dates. The phosphogypsum retarded the setting compared to fluorgypsum. The concretes showed a behavior similar to that of mortars, and the clinker contents increased to $5 \%$ had a negative effect.

In another study, Erdem and Ölmes (11) investigated cementitious pastes of BFS (80-85\%), phosphogypsum (10-18\%) and PC clinker (2-5\%), using a water/solids ratio of 0.25 ; curing was carried out in tap water and synthetic seawater for up to 90 days. The highest compressive and flexural strengths were for the mixture containing $85 \%$ BFS, $10 \%$ phosphoanhydrite and 5\% clinker which showed 61 and $82 \mathrm{MPa}$ (tap water) and 53 and $60 \mathrm{MPa}$ (seawater) after 28 and 90 days respectively. In contrast with Bijen and Niël (10) they reported that a reduction in clinker content resulted in a drastic drop in strength. The specimens cured in synthetic seawater underwent lixiviation and cracking.

O'Rourke et al. (12) reported mortars with binders of slag contents lower than SC, of $66-70 \%$ BFS, $3.4 \%$ calcium sulphate, and relatively high contents of portland cement of $27-30 \%$; the water/solid ratio was of 0.5 and the curing conditions were to $20^{\circ} \mathrm{C}$ under water. All formulations showed very close strength development reaching about $42 \mathrm{MPa}$ at 90 days. Kondo et al. (13) studied formulations of $90 \%$ BFS and 10\% anhydrite with additions of up to $2 \% \mathrm{Ca}(\mathrm{OH})_{2}$ and reported on the evolution of the reactions in pastes with a water/solids ratio of 0.4 for 28 days; they concluded that $0.3 \% \mathrm{Ca}(\mathrm{OH})_{2}$ was optimum, and that ettringite and C-S-H were the main hydration products.

The most recent study found, (5) compared cements for up to 28 days of curing based on two types of BFS of high and low reactivity; the latter slag had lower $\mathrm{CaO}$ and $\mathrm{Al}_{2} \mathrm{O}_{3}$ contents. The cements were activated with $15 \%$ of natural anhydrite and less than $1 \%$ of an alkaline activator such as $\mathrm{KOH}$; an additional series was further added with $1 \%$ $\mathrm{Al}_{2}\left(\mathrm{SO}_{4}\right)_{3}$ and $0.7 \% \mathrm{Ca}(\mathrm{OH})_{2}$. After 1 and 28 days, the more reactive BFS developed 10 and $38 \mathrm{MPa}$ while that the less reactive BFS showed 3 and $32 \mathrm{MPa}$, respectively; however, the addition of $\mathrm{Al}_{2}\left(\mathrm{SO}_{4}\right)_{3}$ and $0.7 \% \mathrm{Ca}(\mathrm{OH})_{2}$ favored the latter, reaching $45 \mathrm{MPa}$ after 28 days, although the 1 day strength was of only $0.7 \mathrm{MPa}$. Backscattered electron imaging microstructures showed extensive formation of ettringite in relatively porous microstructures with many unreacted BFS grains.

The evolution of the hydration reactions emphasizing the early stages, as well as strength development and the characterization of the hydration products over time have not been widely studied for the supersulphated cements. Only a few papers involve curing only for curing times of up to 90 days, nonetheless, the reactions and strength development continue after such curing time; thus investigations involving longer curing times are of interest. As part of a wider outset, this work presents the results of an investigation on the early hydration, strength development, evolution of hydration products and microstructural aspects in supersulphated cements cured for up to 360 days, using fluorgypsum and $\mathrm{PC}$ as the activators. The formulations were characterized by using techniques as Isothermal Conduction Calorimetry, SEM, XRD, Thermal Analysis, EDS (SEM). 


\section{EXPERIMENTAL PROCEDURE}

The granulated blast furnace slag (BFS) used was ground in a steel ball mill to a Blaine surface area of $4600 \mathrm{~cm}^{2} / \mathrm{g}$. The anhydrite was a byproduct of hydrofluoric acid production and is referred as fluorgypsum $(\mathrm{F})$, the cement used was a portland cement (PC) with mineral admixtures. The chemical composition of the starting materials is shown in Table 1.

\subsection{Sample preparation}

Pastes were cast in bars molds of $16 \times 2.5 \times 2.5 \mathrm{~cm}$. Two formulations were prepared, one with $80 \%$ BFS- $15 \% \mathrm{~F}-5 \% \mathrm{PC}$ (referred as $80-15-5$ ) and one with $80 \%$ BFS-10\%F-10\%PC (referred as $80-10-10$ ). The waters/solids ratio for all samples was fixed at 0.4 , using purified water. The cementitious powders were dry mixed in batches of about $6 \mathrm{~kg}$ and once mixed, water was added and samples were mixed again for 4 minutes (14). The molds were filled and vibrated during $40 \mathrm{~s}$ to eliminate air bubbles, then covered with a plastic film to avoid water evaporation and samples were left for setting for a period of $24 \mathrm{~h}$ at $\sim 20^{\circ} \mathrm{C}$. The bars were demolded and cut into cubes of $2.5 \mathrm{~cm}$, using a diamond saw, and were placed in plastic containers for curing under water and also in dry conditions at $\sim 20^{\circ} \mathrm{C}$ for up to 360 days.

\subsection{Characterization}

The compressive strength was measured in cubes of $2.5 \mathrm{~cm}$ at $1,3,7,14,28,90,180$ and 360 curing days by using an automated hydraulic machine (Controls model Sercomp 7) with a constant load rate of $350 \mathrm{~N} / \mathrm{s}$; the reported strengths represent the mean of four specimens. After the mechanical testing, some samples fragments were dried in a vacuum oven at $40^{\circ} \mathrm{C}$ for $48 \mathrm{~h}$ in order to eliminate any free water and to stop the progress of the reactions. Selected samples were ground for $10 \mathrm{~min}$ in a planetary ball mill using agate media, in batches of $10 \mathrm{~g}$ at $300 \mathrm{RPM}$, to pass a $100 \mu \mathrm{m}$ mesh, for characterization by X-ray diffraction (XRD, Phillips X-pert 3040). Such powders were also used for differential thermal analysis and thermogravimetric analysis (DTA/TGA, Perkin Elmer Pyris Dymond) using samples of $15 \mathrm{mg}$ in an air atmosphere at a heating rate of $10{ }^{\circ} \mathrm{C} / \mathrm{min}$. Some fragments of samples were mounted in resin and further ground and polished for surface microstructure analysis with scanning electronic microscope (SEM, Phillips XL30 SEM).

Isothermal conduction calorimetry (ICC), based on the Forrester design $(15,16)$, was carried out to follow the early hydration of samples of about $15 \mathrm{~g}$ at $20^{\circ} \mathrm{C}$. The $\mathrm{SC}$ pastes were mixed inside the cells of the calorimeter, so the collected data included from the hydration time $=0$. Additional characterization was performed on SC hydrated at selected times according to the ICC results. To stop the hydration the non-solidified samples were washed and filtered with methanol, while the solidified samples were crushed and submerged in methanol for $24 \mathrm{~h}$; in both cases the samples were left to evaporate the methanol at $20{ }^{\circ} \mathrm{C}$. The specimens were hand ground for characterization by XRD and DTA/TGA. For such selected times, the samples were also observed under the scanning electron microscope under low vacuum conditions (environmental mode) to analyze the fracture surfaces.

\section{RESULTS AND DISCUSSION}

\subsection{Early hydration}

Calorimetric studies have been a useful tool to understand the hydration reactions by following the heat liberation rate (HLR) of the reacting PC (15), the technique can also be applied to other cementitious materials $(16,17)$. It is generally accepted that the curves of hydration of PC show 5 periods I - preinduction, II - induction, III - acceleration, IV - deceleration and V - diffusion $(6,17)$. Studies of calorimetry for SC cements are scarce in the literature and none of the reports found have information including the moment of mixing the water and the powders. Figure 1 shows the ICC curves of rate of heat liberation total heat liberated vs time for two SC.

The curves of HLR of both cements showed two peaks. The first was labeled as Peak 0, was more intense and appeared within the first hour in both cements; the peak was wider and more intense for the SC 80-15-5 compared to the SC 80-10-10. Peak 0 is attributed to the wetting and the beginning of the hydration reactions, the higher and wider peak 0 from the SC 80-15-5 would originate from the reaction of a higher proportion of fluorgypsum and

TABLE 1. Chemical composition (wt. \%), obtained by X-ray fluorescence

\begin{tabular}{lccccccccr}
\hline Oxide & $\mathbf{S i O}_{2}$ & $\mathbf{C a O}$ & $\mathbf{A l}_{2} \mathbf{O}_{3}$ & $\mathbf{M g O}$ & $\mathbf{F e}_{2} \mathbf{O}_{3}$ & $\mathbf{S O}_{3}$ & $\mathbf{K}_{2} \mathbf{O}$ & $\mathbf{T i O}_{2}$ & $\mathbf{L O I}$ \\
\hline BFS & 33.11 & 38.77 & 10.73 & 8.9 & 0.6 & 3.5 & 0.9 & 1.47 & 1.96 \\
$\mathrm{~F}$ & - & 40.76 & - & - & - & 58.17 & - & - & 0.67 \\
$\mathrm{PC}$ & 12.8 & 63.35 & 2.99 & 1.02 & 2.17 & 3.67 & 0.79 & 0.2 & 12.47 \\
\hline
\end{tabular}




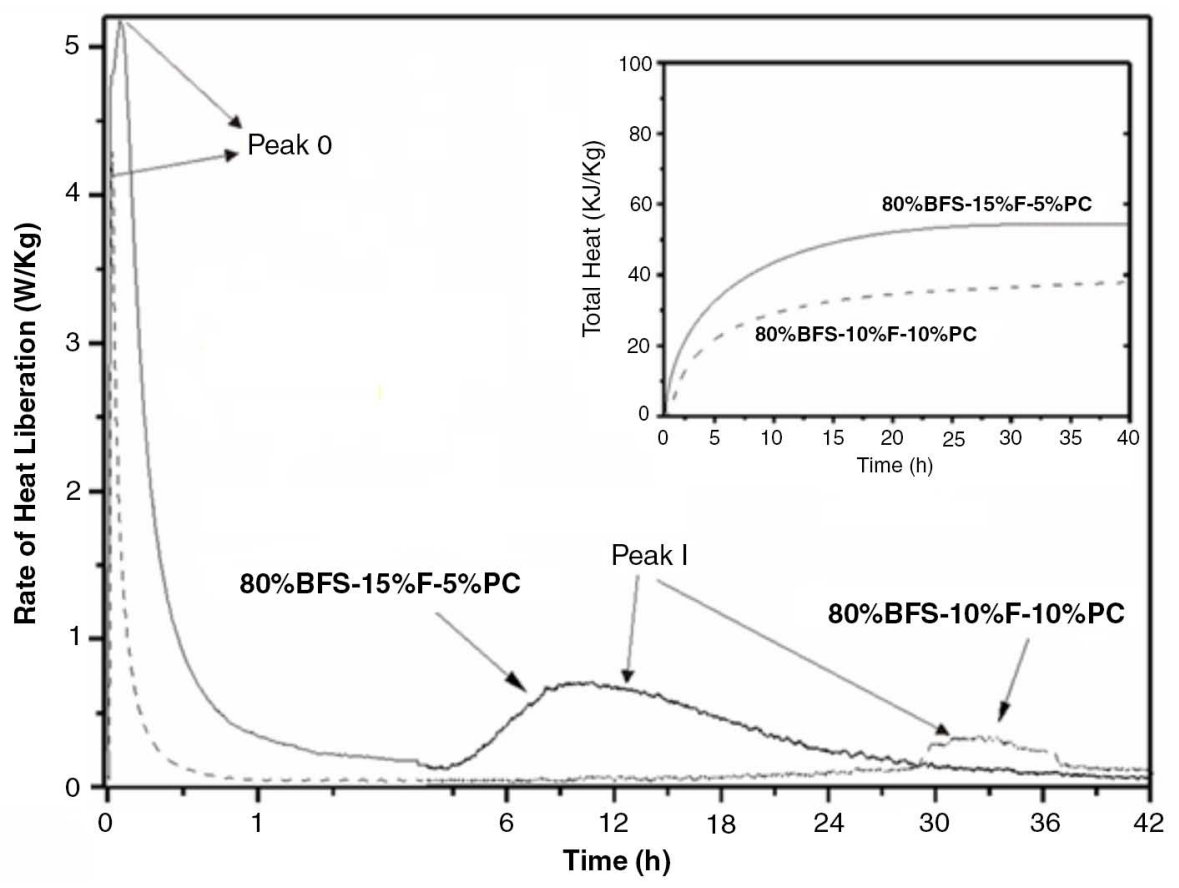

FIGURE 1. Isothermal conduction calorimetry of Supersulphated cements.

possibly from a more intense activation of the BFS. At the end of Peak 0 the HLR declined to values close to zero, circa $0.1-0.2 \mathrm{~W} / \mathrm{kg}$ for both $\mathrm{SC}$, this phenomenon was similar to that reported for the hydration of PC and is called the Dormant period. This period occured as the first hydration products surrounded the grains of BFS creating a semiprotector layer that impeded the evolution of the reactions (6). The extent of the dormant period varied as a function of the composition of the SC, it was considerably shorter for the SC $80-15-5$ of about $3 \mathrm{~h}$, and of $28 \mathrm{~h}$ for $80-10-10$. The duration of the dormant period seems inversely proportional to the amount of fluorgypsum present; i.e at higher fluorgypsum contents the re-activation of the reactions, especially those of BFS, took place at shorter times.

Figure 2 presents the XRD patterns and Figure 3 the corresponding DTA/TGA results of the SC for selected times of hydration according to the features from the ICC curves. For less than hour of hydration, XRD indicated weak reflections of ettringite and gypsum, C-S-H cannot be identified by XRD due to its ill-crystalline nature and the possible low quantities present. In agreement with the above, DTA/TGA clearly indicated weight losses and decomposition peaks at $\sim 90{ }^{\circ} \mathrm{C}$ and a weak peak at $\sim 125^{\circ} \mathrm{C}$ which indicate the early formation of C-S-H $\left(90-125^{\circ} \mathrm{C}\right)$, ettringite $\left(120-130{ }^{\circ} \mathrm{C}\right)$ and gypsum $\left(126-139^{\circ} \mathrm{C}\right)$ $(3,18,19)$. The early formation of C-S-H was also evidenced by the continuous weight losses in the range at $130-640{ }^{\circ} \mathrm{C}(8)$, such losses were higher for the SC 80-10-10, which suggests an intense reaction of the PC that was in greater proportion than in SC 80-15-5. The decomposition at $650-700{ }^{\circ} \mathrm{C}$ could be attributed to the decomposition of $\mathrm{CaCO}_{3}(5,19)$ that was also identified by XRD.

The end of the dormant period was marked by the onset of Peak 1, which is considered a result of a reactivation of the hydration reactions and the intense formation of a new wave of hydration products. For the SC 85-15-5 the maximum of $0.8 \mathrm{~W} / \mathrm{kg}$ appeared at approximately $10 \mathrm{~h}$, which was consistent with Gruskovnjak (5) for SC activated with $15 \%$ of natural anhydrite and $1 \%$ of $\mathrm{KOH}$; however, Kondo et al (13) reported times of peak 1 of 12-84 h for BFS with $10 \%$ anhydrite and up to $2 \% \mathrm{Ca}(\mathrm{OH})_{2}$. On the other hand, the SC 80-10-10 showed a maximum HRL of $0.4 \mathrm{~W} / \mathrm{kg}$ at around $33 \mathrm{~h}$ in agreement with some formulations of reference (13). It is noteworthy that Peak 1 for the SC 85-15-5 was wider and more intense than that of SC 80-10-10, indicating greater progress in the hydration reactions of the former, which in turn reflected in higher values of compressive strength. As the HRL is an indicator of the progress of the reactions, it appears that the SC 85-15-5 benefited more, in terms of reactivity, from the presence of higher fluorgypsum contents than those of PC. The Peak 1 of both SC were of low intensity compared to PC results (15), which is consistent with reports indicating that $\mathrm{SC}$ are of low heat of hydration $(6,8)$.

The second stage of exothermic reactions involves the additional formation of gypsum from the anhydrite, as well as ettringite and C-S-H from the BFS and PC. This was evidenced by the XRD 

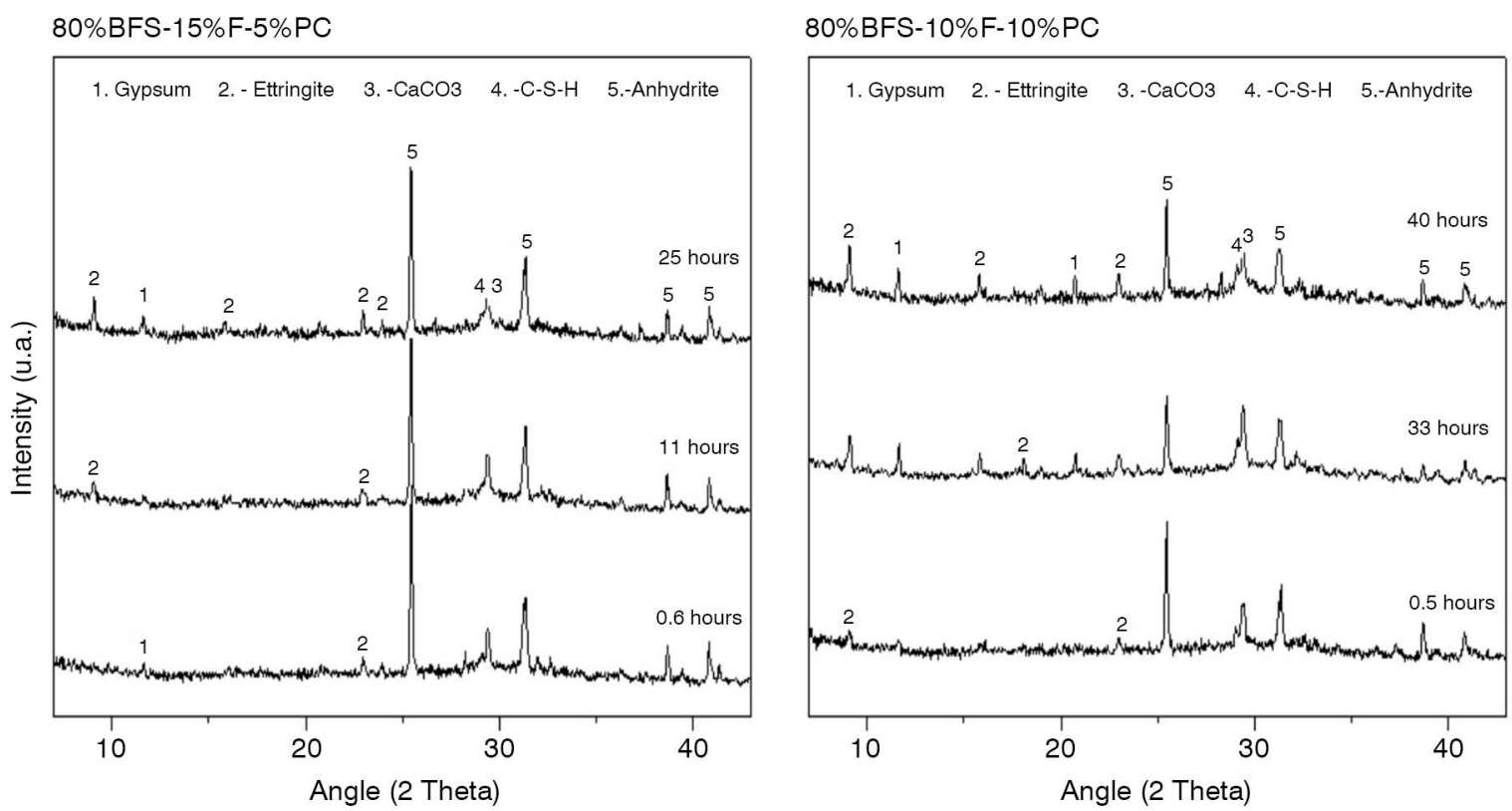

FIGURE 2. X-ray diffraction patterns of the SC $80 \% \mathrm{BFS}-15 \% \mathrm{~F}-5 \%$ and $80 \% \mathrm{BFS}-10 \% \mathrm{~F}-10 \% \mathrm{PC}$ at several hydration times.
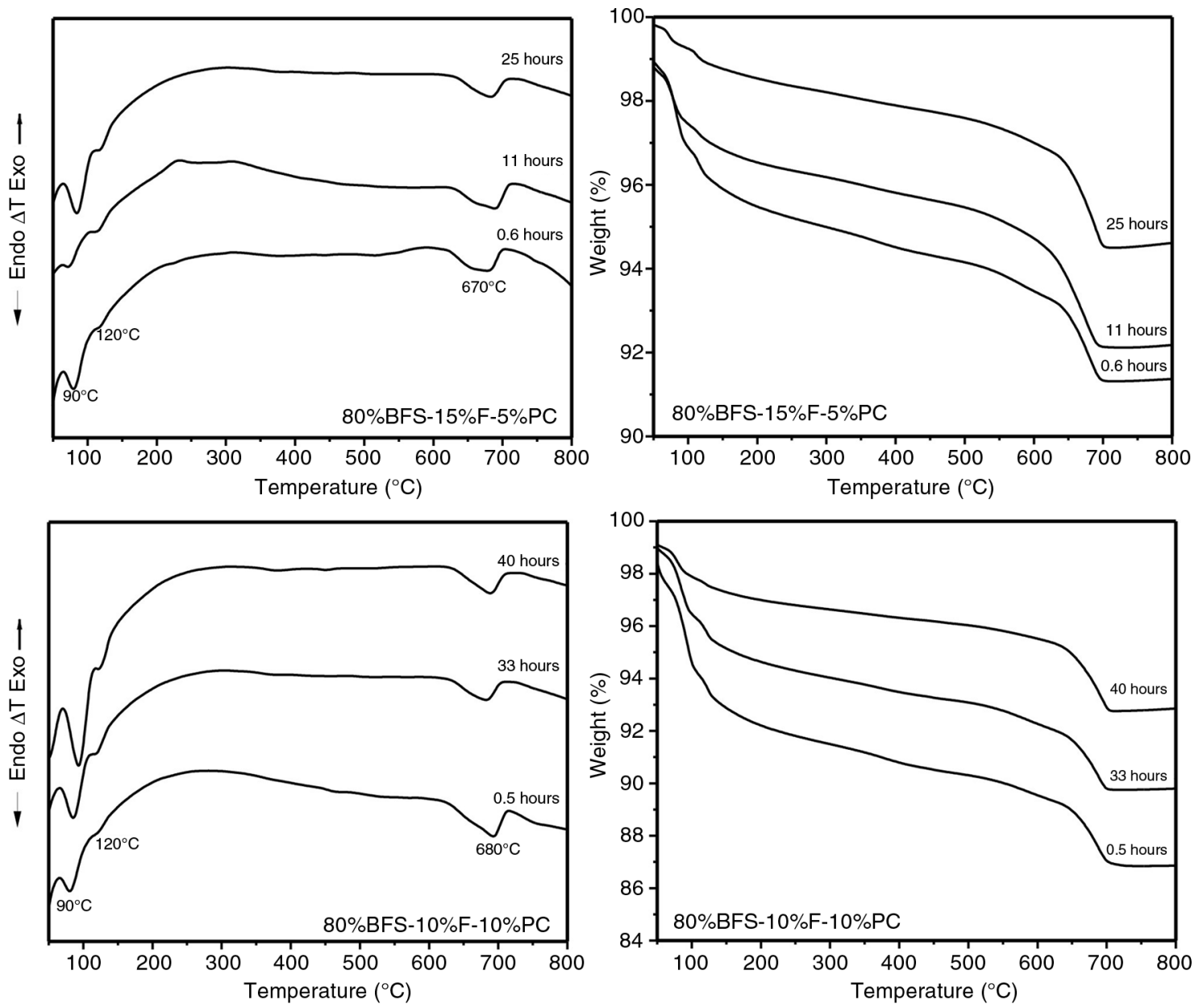

FIgURE 3. TGA and TDA of cement 80-15-5 and 80-10-10 at several times during the early stages of hydration. 
patterns (Fig. 2) and DTA/TGA data (Fig. 3), taken at hydration times corresponding to the maximum and at the end of peak 1; i.e. 11 and $25 \mathrm{~h}$ for $\mathrm{SC}$ $85-15-5$, and 33 and $40 \mathrm{~h}$ for SC $80-10-10$. In both cases the intensity of the ettringite and gypsum reflections increased, relative to the patterns of less than 1 hour; the peaks of $\mathrm{C}-\mathrm{S}-\mathrm{H}$ are uncertain as they overlap with those of the $\mathrm{CaCO}_{3}(8)$. Thermal analysis data confirmed the formation of ettringite, gypsum and C-S-H, as shown by the thermal manifestations as already assigned.

The formation of hydration products during the second wave was also evidenced by electron microscopy as shown in Figure 4, which presents two microstructures obtained on fracture surfaces in secondary electron imaging mode, under low vacuum conditions to avoid the drying of the specimens. The images were taken right after $11 \mathrm{~h}$ for SC 80-15-5 and $33 \mathrm{~h}$ for SC 80-10-10; i.e. at the maximum of peak 1 . The needles of ettringite were clearly observed in the microstructure as well as C-S-H deposited in the surfaces of unreacted angular grains mostly of BFS.

The formation of the C-S-H, ettringite, and gypsum resulted in the setting of the SC pastes during the first 48 hours; however, the evolution of the reactions is far from finished judging by the strength development and the microstructural evolution that followed.

The total heat released (THR) curves, included as an insert in Fig. 1, showed similar patterns for both $\mathrm{SC}$; however, in agreement with the HLR data, the THR for the SC 80-15-5 was grater at the end of the monitoring time. The THR after 2 days were $57 \mathrm{KJ} / \mathrm{kg}$ for SC 85-15-5 and $39.5 \mathrm{KJ} / \mathrm{kg}$ for SC 80-10-10, which are very low compared to those of PC in the order of 260-320 $(15,20)$. The information on the heat of hydration of SC is scarce in the literature, however, some indicated $90 \mathrm{~kJ} / \mathrm{kg}(21), 167-188 \mathrm{~kJ} / \mathrm{kg}$ at 7 days and 188-209 kJ/kg at 28 days (22), whereas (13) reported $25-90 \mathrm{~kJ} / \mathrm{kg}$ after 2 days and $100-175 \mathrm{~kJ} / \mathrm{kg}$ after 5 days. The low slopes of the THR curves after $42 \mathrm{~h}$ suggest that the reactions reached a state of slow progress once the pastes have set; however, the strength developed from 2 days onwards suggest the formation of much more hydration products, which would further increase the THR to values perhaps similar to those reported by other authors.

\subsection{Late hydration}

\subsubsection{Compressive strength}

Figure 5 shows the evolution of compressive strength vs time for cements cured under water and in dry conditions from 1 to 360 days, at $20^{\circ} \mathrm{C}$. In general, the pastes developed strength at relatively high rates. The highest strengths were for the pastes of SC 80-15-5, reaching 26 and $43 \mathrm{MPa}$ after 7 and 28 days, respectively; such trend remained for up to 180 days reaching $58 \mathrm{MPa}$; small changes were noted afterwards. The strength development in the first days is attributed to the formation of ettringite and C-S-H, as discussed above, while the C-S-H is considered the main contributor in later stages $(7,9,10,11,22)$. The reference neat PC cured in dry reported $12 \mathrm{MPa}$ at 1 day, higher than both SC that registered less than $2 \mathrm{MPa}$; however after 14 days the SC 80-15-5 outvalued the PC, which indicates that the hydration of the BFS is slow but its products strengthen the cementitious matrix.

Both SC formulations showed similar patterns of strength development; however the strength decreased when the $\%$ PC augmented. This trend, in which higher calcium sulphate contents were more favorable, contrasts with the report by Erdem and Ölmes (11), but agrees with Bijen and Niël (10). The SC 80-10-10 reached a maximum of $34 \mathrm{MPa}$ at 180 days. The addition of $\mathrm{PC}$ is meant to provide an alkaline environment towards the formation of
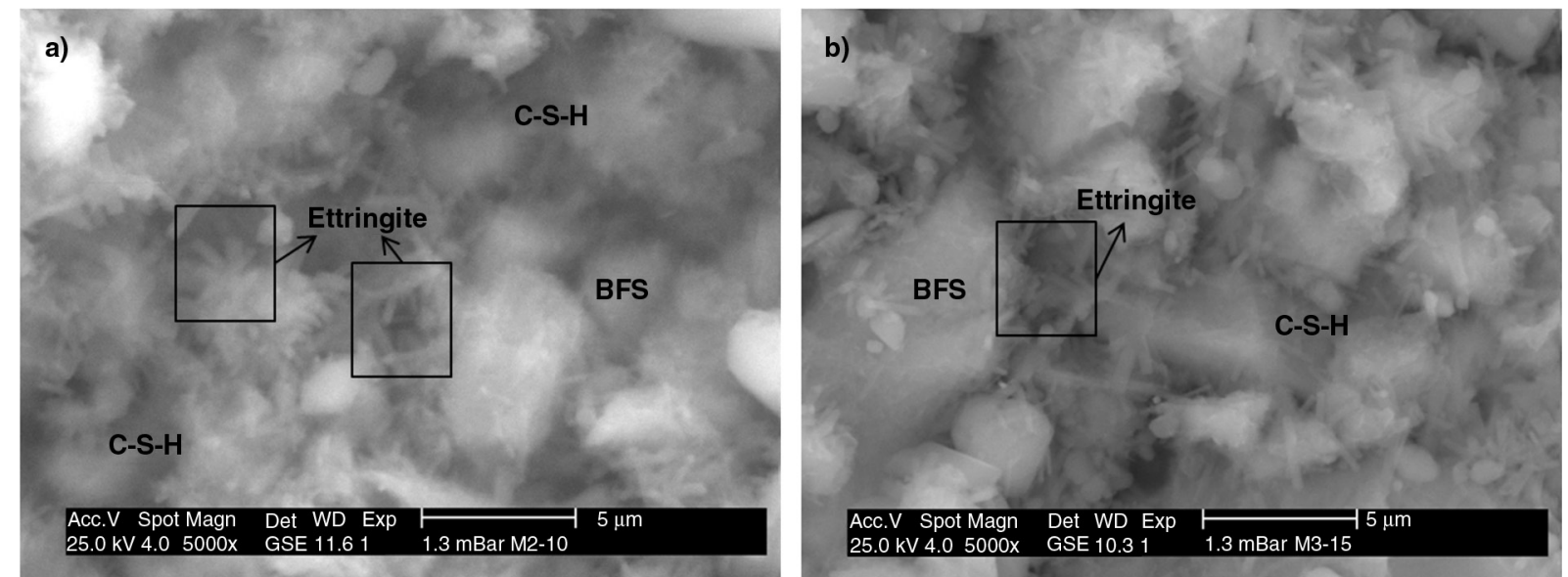

FIGURE 4. Scanning electron microscopy images in secondary electron mode in low vacuum of a) SC 80-10-10 after 33 hours of hydration and b) SC 80-15-5 after 11 hours of hydration. 


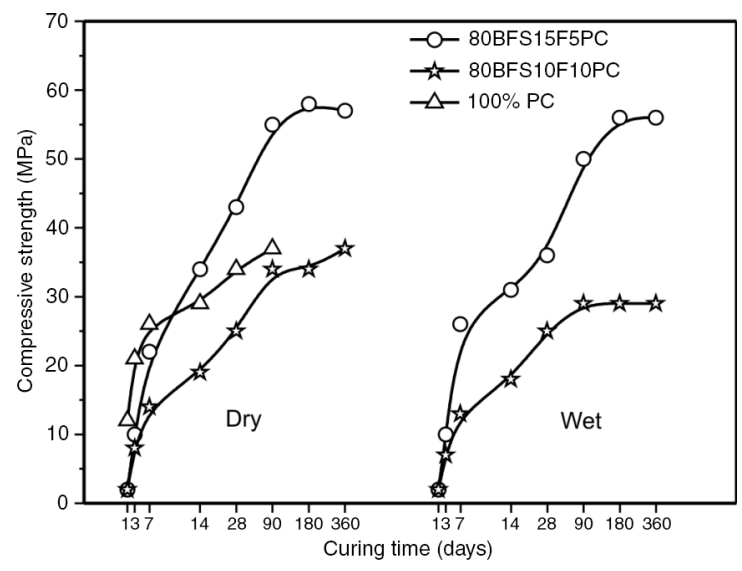

Figure 5. Compressive strength vs. time for the systems of supersulphated cements dry cured and wet cured.

the ettringite in the SC, and also to contribute with hydration products; however an excess of calcium saturates the solution and affects the formation of ettringite, reducing the strengths (8).

For all SC formulations and curing conditions the strength remained fairly stable after 180 days, which indicates that the hydration reactions reached a stage of slow progress. Moreover, for a given composition the difference in strength development between wet and dry curing was not notable, which indicates that these formulations are adequate for both conditions.

\subsubsection{X-Ray diffraction}

Figure 6 presents XRD data corresponding to the SC 80-15-5 cured in dry and wet conditions. Both sets of patterns showed similar features, in that the main phases were ettringite and $\mathrm{C}-\mathrm{S}-\mathrm{H}$, which appeared since the first day and remained during the 360 days of the study. The presence of ettringite from day one, confirms its contribution to strength at early ages; however, the intensity of the peaks did not increase notably over time. As time advances, the amorphous hump from the BFS seems to reduce as it participates in the hydration reactions. The presence of gypsum, noted in the early stages of hydration, was noted only at 1 day in wet curing conditions, in agreement with the results from Figure 5; however, its reflections disappeared for later times.

For both SC the intensity of the reflections of anhydrite decreased with time, as it is consumed in the hydration reactions, increasing the compressive strength. It is noteworthy that although the anhydrite contents are relatively small in the SC, and that the hydration product it forms, i.e. ettringite, is regarded as one of the main hydration product in SC, XRD data showed remaining anhydrite after 1 year describing a limited reactivity. This would result in limited ettringite formation and suggest that the strength development was in great part due to the hydraulic behavior of the BFS forming C-S-H, this would be in agreement with (6). However, XRD evidence of the formation of the latter is complicated by the ill-crystalline nature of the compound that show weak XRD peaks, which also overlap with those of $\mathrm{CaCO}_{3}$ which may form from C-S-H carbonation.

\subsubsection{Thermal analysis}

Figure 7 presents the results of DTA and TGA for the SC 80-15-5 after 1, 28, 180 and 360 days cured in dry conditions. The DTA peaks showed, as previously described, the decomposition of various
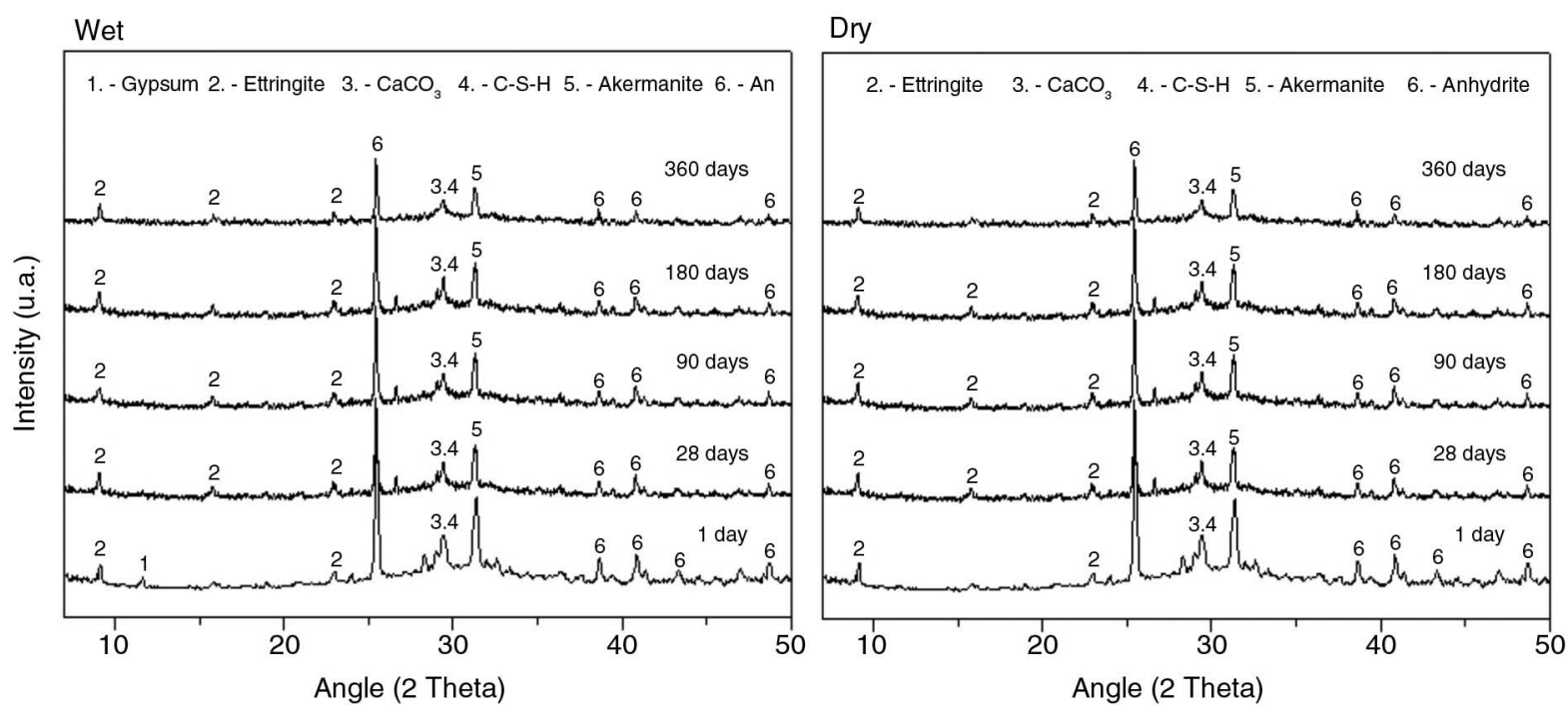

FIGURE 6. X-ray diffraction patterns of the system $80 \% \mathrm{BFS}-15 \% \mathrm{~F}-5 \% \mathrm{PC}$, cured in dry and wet. 

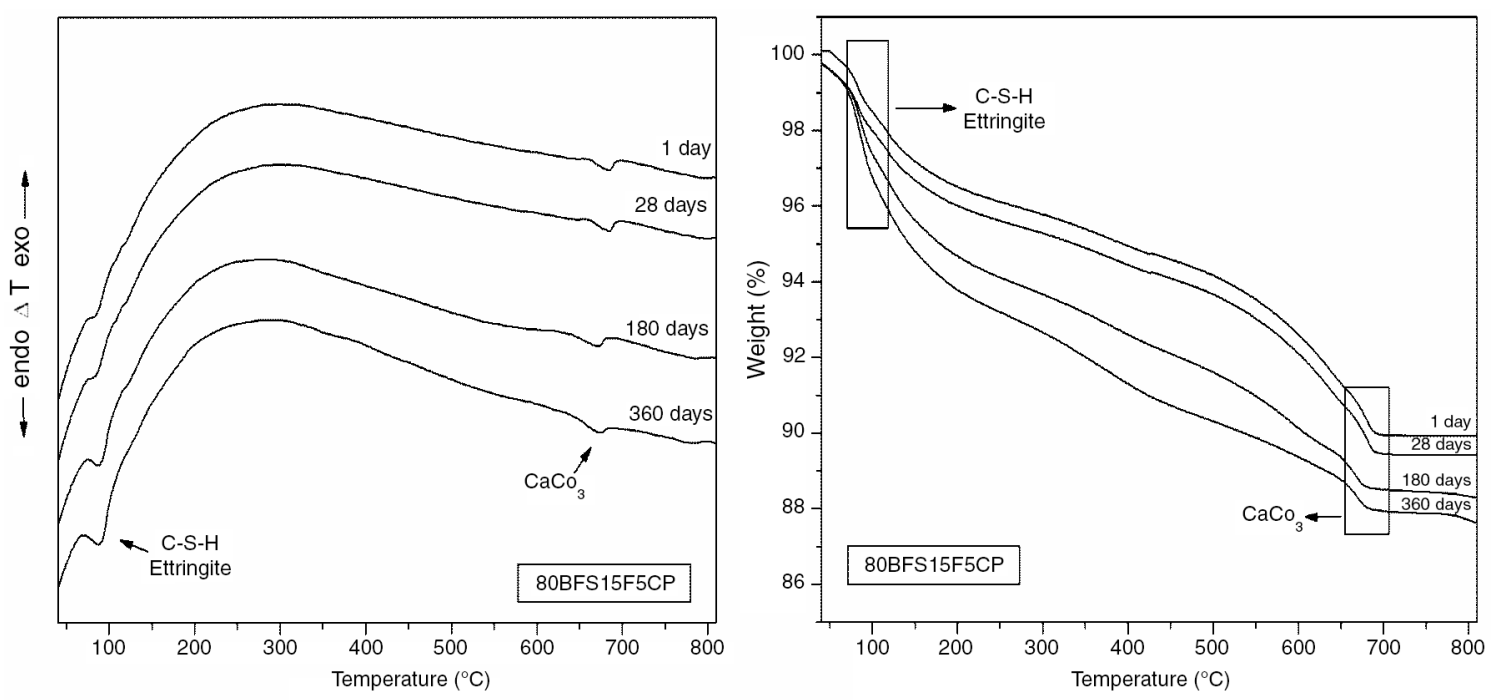

Figure 7. DTA and TGA of supersulphated cement 80-15-5 after of 1,28, 180 and 360 days of hydration in dry conditions.

reaction products. Although $\mathrm{C}-\mathrm{S}-\mathrm{H}$ and ettringite decomposition peaks overlap, XRD evidenced their presence, and the joint peak appeared more intense with time indicating continuous formation of hydration products. Considering the comments on the XRD section in that not all of the anhydrite reacted and that the intensity of the ettringite XRD peaks remained fairly unchanged, this supports the idea that strength development in the late stages was mostly due to C-S-H formation from the BFS.

The TGA results show two main weight loss steps. One extended at $\approx 90-130{ }^{\circ} \mathrm{C}$, corresponding at the decomposition of the C-S-H and ettringite, a continuous loss from $130-640{ }^{\circ} \mathrm{C}$ attributable to $\mathrm{C}-\mathrm{S}-\mathrm{H}(8)$ and another at $\approx 640-670{ }^{\circ} \mathrm{C}$ from the decomposition of calcite. The overall weight losses from $50-640{ }^{\circ} \mathrm{C}$ increased with the curing time, after 1 day the weight loss of $8.8 \%$ suggested an intensive formation of hydration products during the early hydration, the losses increased to $11 \%$ after 360 days, indicating the progressive formation the $\mathrm{C}-\mathrm{S}-\mathrm{H}$ and ettringite in SC.

\subsubsection{Scanning electron microscopy}

Figure 8 shows representative microstructures of polished samples in backscattered imaging mode of a paste of SC 80-15-5 cured for 28 and 360 days under dry conditions, and Figure 9 shows the analogue samples in wet curing. For both ages, the micrographs displayed relatively dense and compact matrices, composed mainly of C-S-H reaction products formed by mostly by a mechanism of dissolution-precipitation, in which the slag grains dissolve when in contact with the water and alkalis, in a mechanism similar to that described for Portland cement (4); the ionic species saturate the solution and then precipitate as hydrated phases. Under wet or dry curing, there were abundant grains of hydrated and partially hydrated slag grains, some small BFS particles presented rims of reaction products, which formed by a mechanism of diffusion. The latter takes place once the majority of the volume initially occupied by water is occupied by hydration products, and the reactions take place on the surface of the slag grains via diffusion of the elements without entering the solution; the composition of the reaction rims was similar to that of the C-S-H from PC (its chemical composition is discussed later). Kondo et al (13) reported $23 \%$ of slag reacted after 28 days, which would be consistent with the presence of many, although not quantified, unreacted BFS grains.

Ettringite is difficult to detect in dried polished samples, not only because it is not the most abundant phases, but also as it is easily decomposed under the drying conditions of the vacuum of the microscope column (23). However EDS spot analysis allows its identification, and some areas containing ettringite were indicated in the microstructures especially at 360 curing days. As the curing time progressed, the matrix of hydration products appeared denser and less unreacted BFS grains remained, this is in agreement with the gains in compressive strength already discussed. In the microstructure of the wet cured simple, some anhydrite crystals were identified as agglomerates of irregular shape with bright spots, this in agreement with the XRD results that indicated its limited reactivity.

Backscattered electron images of microstructures of SC are uncommon in the literature, and those reported from secondary electrons show the predominant formation of ettringite (9). The report of Gruskovnjak et al (5) on SC cements activated with $15 \%$ of natural anhydrite and less than $1 \%$ of $\mathrm{KOH}$, 

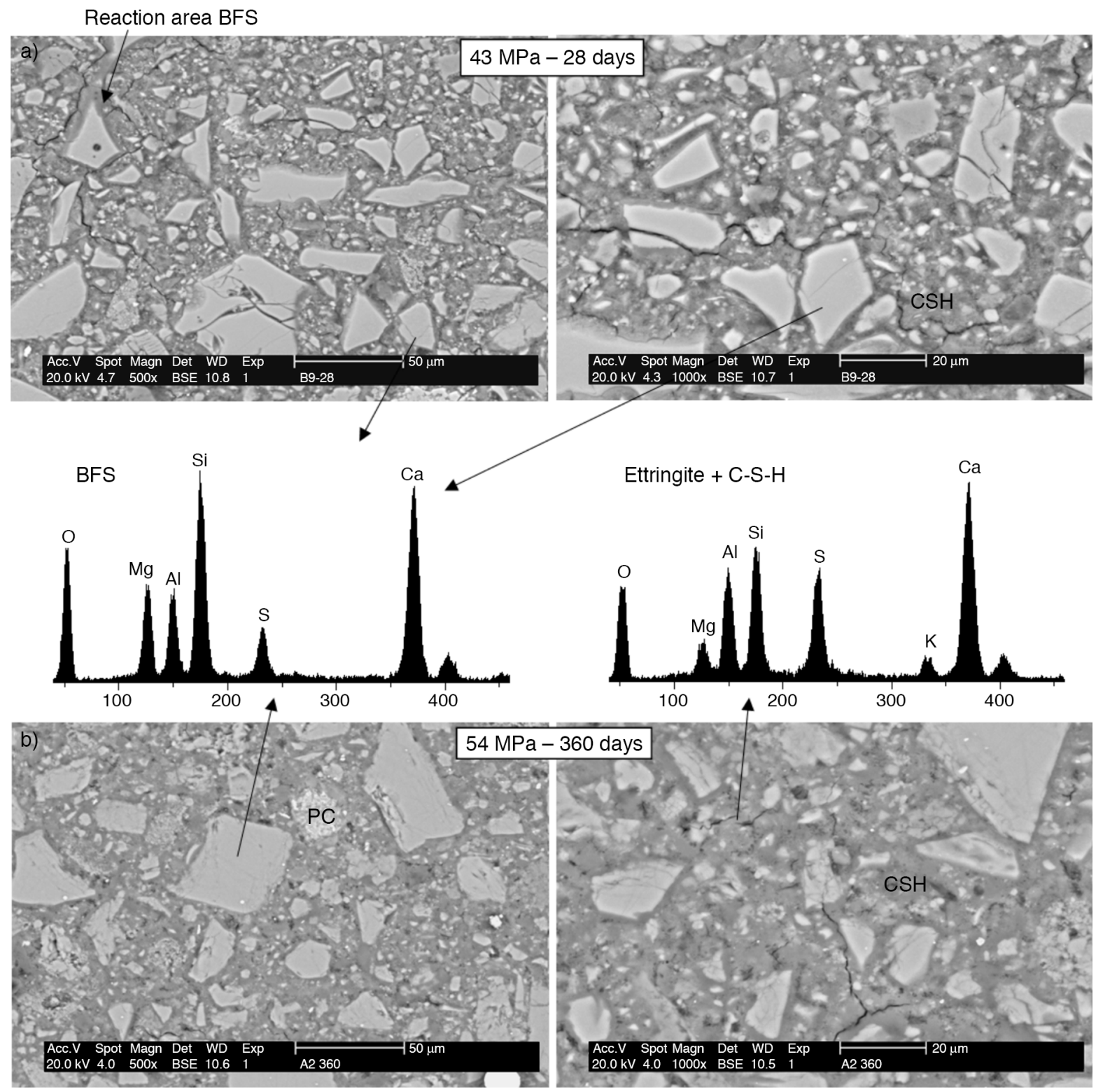

FIGURE 8. Scanning electron microscopy micrographs in backscattered electron imaging mode of SC 80-15-5 cured in dry, a) 28 days and b) 360 days. Spectra of EDS are included for selected spots in the microstructures.

indicated that after 7 and 28 days of curing ettringite prisms were readily noted reaching out from the slag particles into the pore space. Such microstructures were contrastingly more porous than those from this investigation, indicating different kinetics of reactions, perhaps as a result of the substitution of $\mathrm{PC}$ by $\mathrm{KOH}$ to create the necessary alkaline environment. The latter report also indicated the presence of rims of hydration products on the smaller slag grains and that fractured surfaces showed ettringite crystals of 1 micron in length. On the other hand Kondo et al. (13) reported secondary electron images and indicated the formation of ettringite and $\mathrm{CSH}$ but their relative abundance is not discussed.

\subsubsection{Composition of the hydrates}

Figures 10 and 11 present the results of spot analyses for the SC 80-15-5 cured at 28 and 360 days under dry conditions. The results are shown in ternary diagrams $\mathrm{Ca}-\mathrm{Si}-\mathrm{Al}$ and $\mathrm{Ca}-\mathrm{S}-\mathrm{Al}$, and the analyses are gathered in two groups of reaction products, i.e. OP outer products, formed in the spaces initially occupied by water, and IP inner products, formed within the boundaries of slag grains. The diagrams also included, the composition of reference compounds such as ettringite $\left(\mathrm{C}_{3} \mathrm{~A} \cdot \mathrm{C} \hat{\mathrm{S}} \cdot 32 \mathrm{H}\right)$, calcium sulphate $(\mathrm{CS})$ and those of $\mathrm{CSH}$ from $\mathrm{PC}$ and BFS as measured in neat $\mathrm{PC}$ and PC-BFS blends, and BFS and PC-BFS blends (24). 


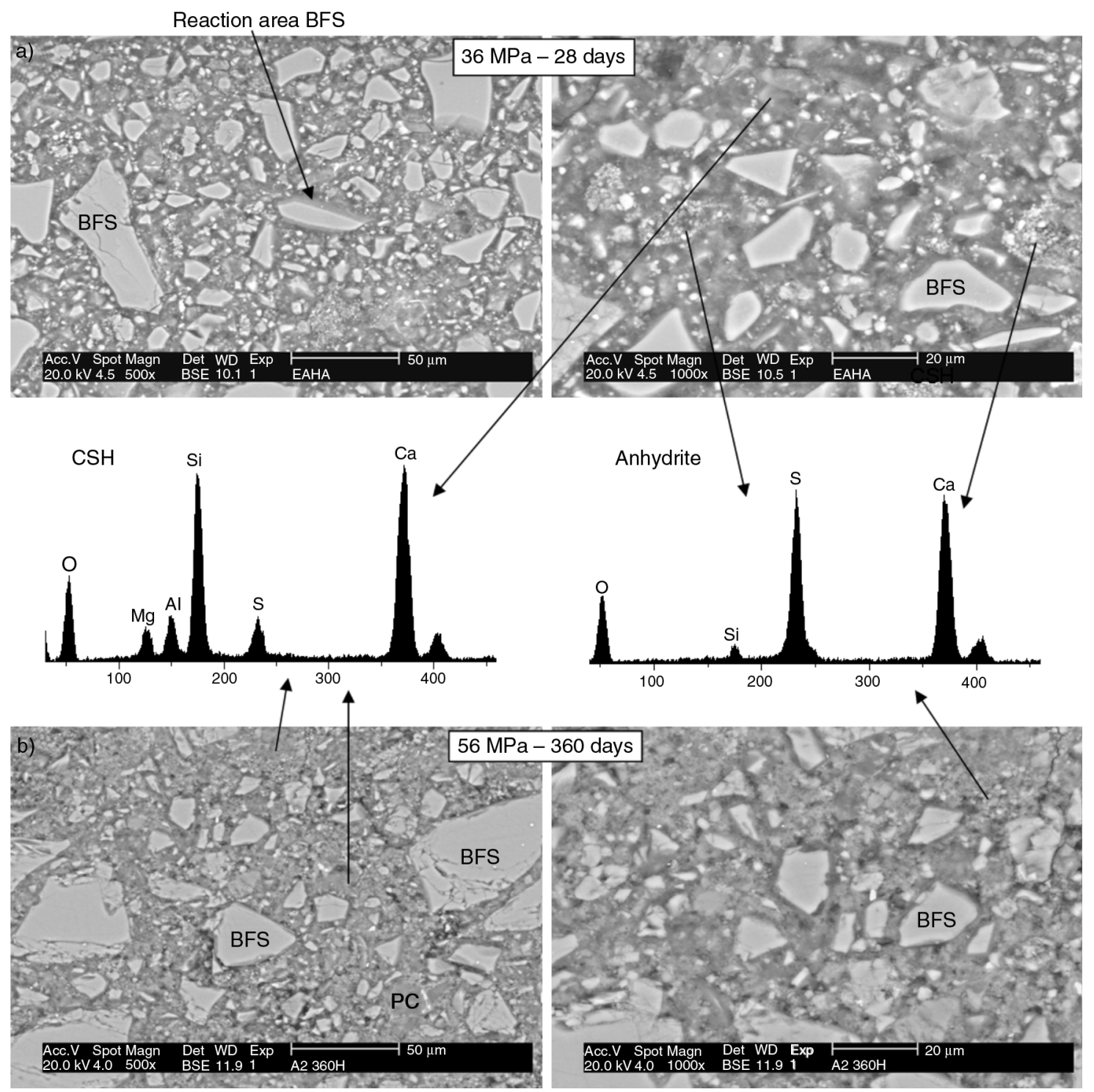

FIGURE 9. Scanning electron microscopy micrographs in backscattered electron imaging mode of SC 80-15-5 cured in wet, a) 28 days and b) 360 days. Spectra of EDS are included for selected spots in the microstructures.

In Fig. 10 (Ca-Si-Al), after 28 days the composition of the OP (matrix of hydration products) plotted close to the composition commonly reported for C-S-H from PC or BFS-PC $(24,25)$ but with more Ca, and less $\mathrm{Al}$ and $\mathrm{Si}$. The ratio $\mathrm{Si} / \mathrm{Ca} \sim 0.33$ is lower than that of $\mathrm{PC}$ reported at $\sim 0.5$ (26). On the other hand, the IP (hydration products within BFS grains) show a composition with a ratio of $\mathrm{Si} / \mathrm{Ca} \sim 0.73$, that plotted closer to the reported composition of C-S-H from the $\mathrm{PC}$ and BFS fractions in PC-BFS composite cements (24). There are clear differences in the chemical composition of the IP and OP, this would be acceptable as it is expected that the OP would include the presence of ettringite finely intermixed as formed from the initial stages of hydration as discussed below.

As time progressed to 360 days in Fig. 10, the composition of the IP and OP showed some changes.
First the results plotted closer to each other, indicating a more similar chemical composition; nonetheless the OP showed lower Al contents. The only source of $\mathrm{Al}$ is the BFS, so the presence of $\mathrm{Al}$ in the OP would indicate the actual dissolution of BFS during the reaction process. Moreover, the increased $\mathrm{Al}$ and $\mathrm{Si}$ content in the OP from 28 to 360 days indicates that after 28 days the BFS continued reacting via a mechanism of dissolutionprecipitation, and that possible diffusion of $\mathrm{Si}$ and Al that modified the overall composition of the OP. Both OP and IP plotted closer to the composition of CSH from a CP and BFS fractions from PC-BFS blended cements. These results indicate that the predominant hydration product is a CSH from the BFS reaction, in agreement with the already discussed results. 

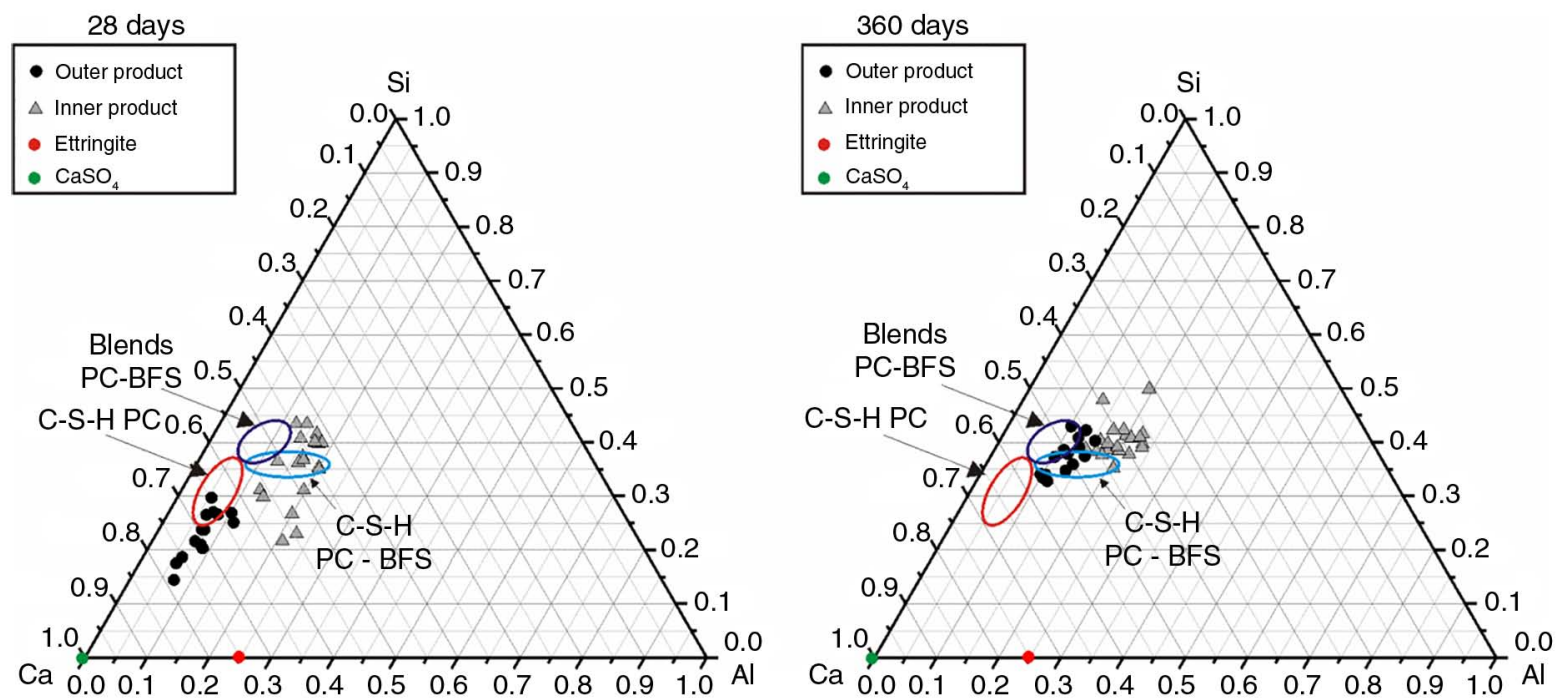

FIGURE 10. Chemical composition of hydration products of supersulphated cement: $\mathrm{Ca}-\mathrm{Si}-\mathrm{Al}$ at 28 and 360 days. Circled areas references (25).
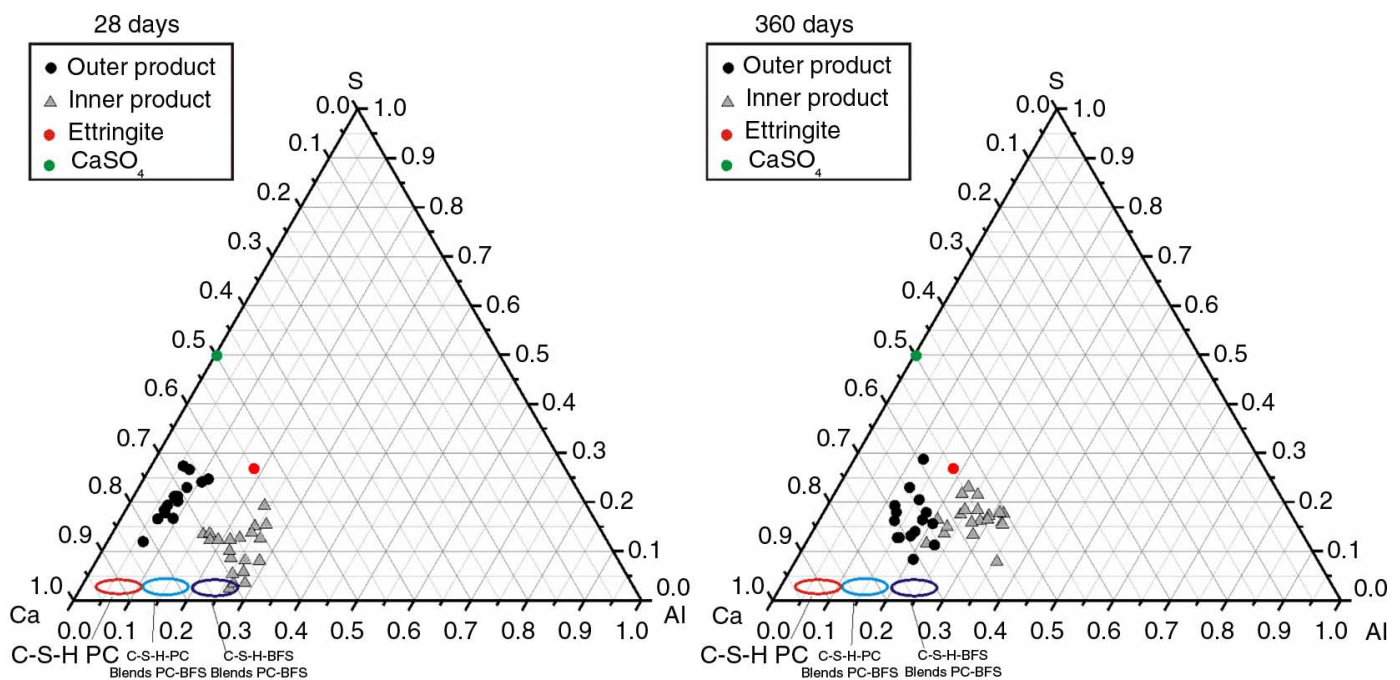

FIGURE 11. Chemical composition of hydration products of supersulphated cement: $\mathrm{Ca}-\mathrm{S}-\mathrm{Al}$ at 28 and 360 days. Circled areas references (25).

Figure 11 present data in the format $\mathrm{Ca}-\mathrm{S}-\mathrm{Al}$, the reference compositions used in Figure 10 were also included. After 28 days the compositions of IP and OP were different in that the former showed lower S and higher $\mathrm{Al}$ contents, this makes sense as the only source of $\mathrm{Al}$ is the BFS and the only source of $\mathrm{S}$ is the calcium sulfate. Both IP and OP compositions plotted from the CSH compositions towards the reference composition of ettringite. The composition of the IP leans more towards the reported composition of C-S-H from BFS in BFS-PC composites (24). After 360 days, the compositions of IP and OP plotted closer to each other, and some points lied closer to the reference composition of ettringite, i.e. higher
S contents in both IP and OP. Many points of IP and OP lied between the composition of ettringite and C-S-H, suggesting that the excited volumes during the EDS analysis included information from both phases, which in turn may suggest a very intimate intermixing of such phases in the matrix of hydration products.

\section{FURTHER COMMENTS}

The cementitious pastes reported excellent mechanical properties and showed stability and hydraulic behavior for up to one year; the SC 80-15-5 showed to be the most adequate composition reaching 42 and $57 \mathrm{MPa}$ at 28 and 360 days 
of curing. The slag participated intensively in the hydration reactions, as evidenced by the dark green tone of the inner part of the cubic specimens (Fig. 12), similar to that observed for heavily reacted BFS in cements activated by various alkalis.

The reaction mechanisms, strength development, evolution of hydration products and microstructural aspects of supersulphated cements was investigated for the first 48 hours as well as for longer periods of time and using an a wider experimental approach than previous reports. The main products of hydration of SC are ettringite and C-S-H; however, the literature differs regarding their formation, most mentioning that ettringite is formed in the first days, and C-S-H afterwards. Few reports mention the occurrence of both phases simultaneously from the early stages of hydration.

The initial setting and hardening is associated to the simultaneous formation of calcium sulphoaluminates and C-S-H from the first hours, evidenced by XRD (Fig. 2) and thermal analysis (Fig. 3), forming a porous and weak microstructure SEM (Fig. 4). The microstructure and assemblage of hydration products evolved with time and densified (Figs. 8 and 9), increasing the compressive strength (Fig. 5); the chemical composition of the C-S-H changed over time (Figs. 10 and 11) towards a more homogeneous composition. The amounts of ettringite and C-S-H increased (Figs. 6 and 7) over time, and in contrast to Portland cement where ettringite may cause expansion and cracking, ettringite was key for strength development in SC.

The hydration reactions of the investigated supersulphated cements can be simplified as:

$$
\begin{gathered}
\mathrm{BSF}\left(\mathrm{SiO}_{2}+\mathrm{CaO}+\mathrm{Al}_{2} \mathrm{O}_{3}\right) \\
+ \\
\mathrm{F}\left(\mathrm{CaO}+\mathrm{SO}_{3}\right) \\
+ \\
\mathrm{PC}\left(\mathrm{SiO}_{2}+\mathrm{CaO}+\mathrm{Al}_{2} \mathrm{O}_{3}+\mathrm{Fe}_{2} \mathrm{O}_{3}\right) \\
+ \\
\text { Water }\left(\mathrm{H}_{2} \mathrm{O}\right) \\
\downarrow \\
\text { Ettingite }\left(3 \mathrm{CaO} \cdot \mathrm{Al}_{2} \mathrm{O}_{3} \cdot 3 \mathrm{CaSO} \mathrm{C}_{4} \cdot 32 \mathrm{H}_{2} \mathrm{O}\right) \\
+ \\
\mathrm{C}-\mathrm{S}-\mathrm{H}\left(\mathrm{CaO} \cdot \mathrm{SiO}_{2} \cdot \mathrm{H}_{2} \mathrm{O}\right) \\
+ \\
\text { unreacted } \mathrm{F}\left(\mathrm{CaSO}_{4}\right)
\end{gathered}
$$

The bonds of $\mathrm{Ca}-\mathrm{O}$, Si-O and $\mathrm{Al}-\mathrm{O}$ are broken as the slag dissolves in contact with the activating aqueous media. Other ions from the Portland cement and calcium sulphate complement the composition for the precipitation of ettringite and C-S-H. A sulphatic medium and an alkaline activator like

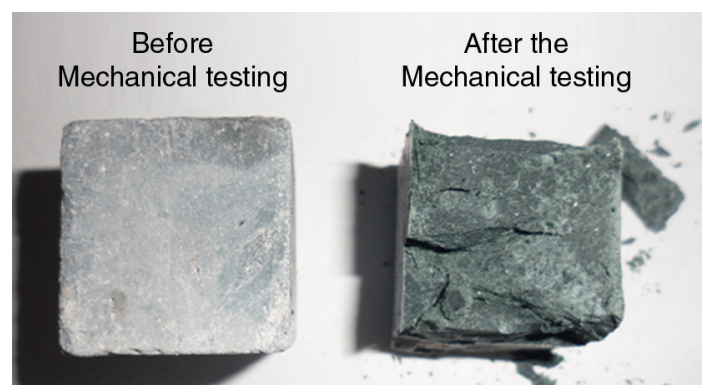

FIGURE 12. Supersulphated cement 80-15-5 after 360 days, before and after the mechanical test.

Portland cement are needed; however, the results indicate that the latter needs to be kept low.

\section{CONCLUSIONS}

- The main hydration products of supersulphated cements were C-S-H and Ettringite. These products precipitated since the first hours of hydration, forming a porous and weak microstructure; with time and up to one year, the C-S-H and Ettringite consolidated the microstructure and increased the compressive strength. The cements showed hydraulic behavior after curing under water.

- The strength properties of the supersulphated cements benefit more by the presence of higher contents of fluorgypsum than from higher contents of Portland cement. The calcium sulphate activates the slag reactions promoting the formation of ettringite and C-S-H from the early hours of hydration, and the process continues for up to one year.

- The composition $80 \%$ slag, 15\% fluorgypsum and $5 \%$ portland cement, resulted the best composition for strength development and hydraulic behavior.

- The low heat of hydration measured for the supersulphated binders, makes them attractive for large mass works, also the results were in agreement with those found in the literature.

- The composition of the C-S-H formed as a reaction product, varied over time from 28 to 360 days towards a more homogeneous composition.

- The cements investigated are economically and ecologically advantageous by the incorporation of low-cost wastes and the reduction in the consumption of portland cement. The mechanical properties are also advantageous from a technological point of view.

\section{ACKNOWLEDGMENTS}

Bazaldua-Medellin acknowledges the scholarship from Conacyt. Research funded by project Conacyt Ciencia Básica 53563. 


\section{REFERENCES}

1. Escalante García, J.I. (2002) Alternative materials to Portland cement (in Spanish). Avance y perspectiva. 21, 79-88

2. Gartner, E. (2004) Industrially interesting approaches to "low-CO2" cements. Cem Concr Res. 34, 1489-98. http:// dx.doi.org/10.1016/j.cemconres.2004.01.021.

3. Mehrotra, V.P.; Sai, A.S.R.; Kapur, P.C. (1982) Plaster of Paris Activated Supersulphated Slag Cement. Cem Concr Res. 12, 463-473. http://dx.doi.org/10.1016/0008-8846(82) 90061-8.

4. Taylor, H.F.W. (1997) Cement Chemistry, Academic Press, Inc New York.

5. Gruskovnjak, A.; Lothenbach, B.; Winnefeld, F.; Figi, R.; Ko, S.C.; Adler, M.; Mäder, U. (2008) Hydration mechanisms of super sulphated slag cement. Cem Concr Res. 38, 983-992. http://dx.doi.org/10.1016/j.cemconres.2008. 03.004 .

6. Fernández Jiménez, A.; Puertas, F.; Fernández Carrasco, L. (1996) Alkaline-sulphate activation processes of a spanish blast furnace slag. Mater. Construcc. 46 [241], 23-37.

7. Ko, S.C. (2002) Alcali activated supersulphated blinder. United States Patent. Patent No: US 6,409,819 B1.

8. Hewlett, P.C. (2004) Leaś Chemistry of Cement and Concrete, Elsevier Science \& Technology Books Publishing.

9. Midgley, H.G.; Pettifer, K. (1971) The micro structure of hydrated super sulphated cement. Cem Concr Res. 1, 101-104. http://dx.doi.org/10.1016/0008-8846(71)90086-X.

10. Bijen, J.; Niël, E. (1981) Supersulphated cement from blastfurnace slag and chemical gypsum available in the Netherlands and neighbouring countries. Cem Concr Res. 11, 307-322. http://dx.doi.org/10.1016/0008-8846(81)90104-6.

11. Erden, E.: Ölmez, H. (1993) The mechanical properties of supersulphated cement containing phosphogypsum. Cem Concr Res. 23, 115-121. http://dx.doi.org/10.1016/00088846(93)90141-U.

12. O'Rourke, B.; McNally, C.; Richardson, M.G. (2009) Development of calcium sulfate-ggbs-Portland cement binders. Constr and Build Mat. 23, 340-346. http://dx.doi. org/10.1016/j.conbuildmat.2007.11.016

13. Kondo, R.; Daimon, M.; Song, C.; Jinawath, S. (1980) Effect of lime on the hydration of super-sulfated slag cement. American Ceramic Society Bulletin. 59 [8], 848-851.

14. Norma ASTM C309-94. Standard practice for mechanical mixing of hydraulic cement pastes and mortars of plastic consistency.
15. Escalante García, J.I.; Sharp, J.H. (2000) The effect of temperature on the early hydration of Portland cement and blended cements. Adv Cement Res. 12 [3], 121-130. http:// dx.doi.org/10.1680/adcr.2000.12.3.121.

16. Magallanes Rivera, R.X.; Escalante García, J.I.; Gorokovsky, A. (2009) Hydration reactions and microstructural characteristics of hemihydrate with citric and malic acid. Constr Build Mat. 23, 1298-1305. http://dx.doi.org/10.1016/j. conbuildmat.2008.07.022.

17. Shi, C.; Day, R.L. (1996) Some factors affecting early hydration of alkali-slag cements. Cem Concr Res. 26 [3], 439-447. http://dx.doi.org/10.1016/S0008-8846(96)85031-9.

18. Matscei, T.; Lothenbach, B.; Glasser, P.F. (2007) Thermodynamics properties of Portland cement hydrates in the system $\mathrm{CaO}-\mathrm{Al}_{2} \mathrm{O}_{3}-\mathrm{SiO}_{2}-\mathrm{CaSO}_{4}-\mathrm{CaCO}_{3}-\mathrm{H}_{2} \mathrm{O}$. Cem Concr Res. 37, 1379-1410. http://dx.doi.org./10.1016/j. cemconres.2007.06.002.

19. Martínez Aguilar, O.A.; Castro Borges, P.; Escalante García, J.I. (2010) Hydraulic binders of fluorgypsumportland and blast furnace slag, stability and mechanical properties. Constr Build Mat. 24, 631-639. http://dx.doi. org/10.1016/j.conbuildmat.2009.11.006.

20. Escalante García, J.I.; F. Fuentes, A.; Gorokhovsky, A.; Fraire Luna, P.E.; Mendoza Suarez, G. (2003) Hydration products and reactivity of blast-furnace slag activated by various alkalis. J. Am. Ceram Soc. 86 [12], 2148-2153. http://dx.doi.org/10.1111/j.1151-2916.2003.tb03623.x.

21. Matschei, T.; Bellmann, F.; Stark, J. (2000) Hydration behavior of sulphate-activated slag cements. Adv. Cem. Res. 18 [5], 167-178. http://dx.doi.org/10.1680/adcr.2005.17.4.167.

22. Odler, I. (2000) Special Inorganic Cements, E \& FN Spon.

23. Gomez Zamorano, L.Y. (2004) Geothermal waste as a replacement material of portland cement pastes. $\mathrm{PhD}$ Thesis, Metallurgical and Ceramic Engineering. Cinvestav Unidad Saltillo, Mexico.

24. Escalante Garcia, J.I.; Sharp, J.H. (2004) The chemical composition and microstructure of hydration products in blended cements. Cem Concr Comp. 26, 967-976. http:// dx.doi.org/10.1016/j.cemconcomp.2004.02.036.

25. Shi, C.; Fernández Jiménez, A.; Palomo, A. (2011) New cements for the $21^{\text {st }}$ century: The pursuit of an alternative to Portland cement. Cem Concr Res. 41, 750-763. http:// dx.doi.org/10.1016/j.cemconres.2011.03.016.

26. Escalante García, J.I.; Sharp J.H. (1999) Variation in the composition of C-S-H gel in Portland cement pastes cured at various temperatures. J. Am. Ceram. Soc. 82 [11], 3237-3241. http://dx.doi.org/10.1111/j.1151-2916.1999.tb02230.x. 